\title{
Hair elements and healthy aging: a cross-sectional study in Hainan Island, China
}

\author{
Zhe Hao $\cdot$ Yonghua Li $\cdot$ Yuan Liu \\ Hairong Li $\cdot$ Wuyi Wang $\cdot$ Jiangping Yu
}

Received: 25 April 2015/Accepted: 22 July 2015/Published online: 31 July 2015

(C) Springer Science+Business Media Dordrecht 2015

\begin{abstract}
Healthy aging is considered as the core issue of aging population. Centenarians are a symbol of healthy aging. Concentration of elements in hair is an indicator of micronutrient status, which can affect the human health. In the present study, we investigated element concentrations in the scalp hair of 255 healthy centenarians from Hainan Island, China. The pattern of intergenerational transmission of elements and the effects of confounders such as sex, age, education level, smoking habits, alcohol intake, and frequency of hospitalization on hair element concentrations were assessed. For most elements, the load in hair increased significantly through intergenerational transmission (i.e., centenarians $<$ children $<$ grandchildren). Our
\end{abstract}

Z. Hao · Y. Li $(\bowtie) \cdot$ Y. Liu $\cdot$ H. Li · W. Wang · J. Yu Key Laboratory of Land Surface Pattern and Simulation, Institute of Geographical Sciences and Natural Resources Research, Chinese Academy of Sciences, Beijing 100101, China

e-mail: yhli@igsnrr.ac.cn

Z. Hao · Y. Liu

University of Chinese Academy of Sciences,

Beijing 100049, China

Z. Hao

Key Laboratory of Engineering Oceanography, Second Institute of Oceanography, SOA, Hangzhou 310012, China

Y. Li $\cdot$ H. Li $\cdot$ W. Wang $\cdot$ J. Yu

Beijing Key Laboratory of Environmental Damage

Assessment and Remediation, Beijing, China results also demonstrated that female centenarians had significantly higher concentrations of $\mathrm{Ca}, \mathrm{Mg}, \mathrm{Mn}, \mathrm{Se}$, and $\mathrm{Sr}$ but lower levels of $\mathrm{Cr}$ and P. The Mn level was statistically significantly lower in the primary studies group. Alcohol intake was positively associated with $\mathrm{Cd}$ and $\mathrm{Na}$ levels, whereas smoking habits showed no significant effect on all the elements. Furthermore, the frequency of hospitalization was significantly positively associated with $\mathrm{Cd}, \mathrm{Cu}$, and $\mathrm{Pb}$ concentration. Moreover, our analysis suggested that adequate concentrations of Fe and Se might increase the life span of centenarians, whereas excessive concentrations of $\mathrm{P}$ and $\mathrm{Pb}$ were harmful to health and reduced life span. These results imply that element concentrations could be manipulated as a therapeutic modality in geriatric disease. They might also provide reference values for diseased subjects, allowing improved diagnoses and more effective therapies, which might support effective policies on health and aging.

Keywords Healthy aging - Centenarians .

Elements · Intergenerational transmission .

Confounders

\section{Introduction}

Populations around the world are aging rapidly, leading us into uncharted demographic territory. According to the 2012 revision of the Population Division of the United Nations Department of 
Economic and Social Affairs of the United Nations Secretariat, those aged $\geq 60$ years are the fastest growing group globally, the proportion of which has risen from $8 \%$ of the world's population in 1950 to $11.7 \%$ in 2013 and is expected to reach $21.2 \%$ in 2050 (UN DESA 2013). Aging is widely regarded as one of the most significant risks to global prosperity, because it has potentially profound economic, social, and political implications (Beard et al. 2011). As a less-developed country, China will experience a more dramatic change than others, with the proportion of the population aged $\geq 60$ years expected to rise from $13.9 \%$ in 2013 to $32.8 \%$ in 2050 (UN DESA 2013). The pace of this change means that China will have a much briefer period than other countries to adjust and to establish the infrastructure and policies necessary to meet the needs of its rapidly shifting demographic.

Centenarians are a symbol of health and longevity in most societies (Ozaki et al. 2007) due to their healthy disposition and maintenance of a healthy lifestyle (Franchini and Mannucci 2007; Ozaki et al. 2007; Perls et al. 2002), and many studies have focused on this group to estimate the prevalence of super-longevity in communities or to explain its influencing factors (Christensen and Vaupel 1996; Robine and Paccaud 2005; Wilkinson and Sainsbury 1998). According to the New England Centenarian Study, the largest study of centenarians in the world, approximately $90 \%$ of centenarians remain disability free until 93 years of age, while approximately $43 \%$ develop age-related diseases before 80 years, $42 \%$ develop disease after 80 years, and $15 \%$ have not developed disease by 100 years (Andersen et al. 2012). In China, the number of centenarians has risen dramatically from 17,877 in 2000 to 35,934 in 2010 (China NBS 2001, 2011).

Biomonitoring is an approved technique that assesses the impact of chemical elements present in the environment on living organisms (US EPA 1979). Hair is an excretory tissue for essential, nonessential, and potentially toxic elements. In general, the amount of an element irreversibly incorporated into growing hair is useful in assessing the health and nutritional status of target populations ( $\mathrm{Li}$ et al. 2012). Therefore, hair element analysis provides an indirect test for physiological excess, deficiency, or maldistribution of elements in the body. Clinical research indicates that the concentration of specific elements in hair, particularly potentially toxic elements, is highly correlated with certain pathological disorders. Moreover, trace elements, as well as vitamins and minerals, play an important role in maintaining metabolic homeostasis in the elderly and in preventing many age-associated diseases (Pike and Chandra 1995; Schmidt 1991). Compared with other biological specimens, such as blood and urine, hair sampling is less invasive, more convenient for storage and transport, and less hazardous (Li et al. 2012), making it an attractive biomonitoring substrate.

Previous studies of centenarians have mainly focused on their health status in relation to a specific area of gerontological epidemiology, such as mental (Selim et al. 2005), cognitive (Andersen-Ranberg et al. 2001), clinical (Evert et al. 2003; Stathakos et al. 2005), and physical epidemiology (Motta et al. 2005; Stathakos et al. 2005). Element concentrations in the tissues of healthy centenarians have not been widely analyzed, yet they can be used as reference data leading to an improved assessment of the aging process and the micronutrient status of this group (Li et al. 2012). It has been reported that several characteristics such as age, sex, ethnicity, nutrition, and geographical location might affect element concentrations in human hair (Savarino et al. 2001; Steinmaus et al. 2000; Wilhelm et al. 1991). However, to date, there has been a lack of detailed research on the effects of these factors on element concentrations in centenarian hair. Aging is associated with changes in metabolism and status of various nutrients (Ahluwalia et al. 2000). There is some evidence that hematologic variables made up of elements such as hemoglobin and hematocrit may decline with aging in humans (Preziosi et al. 1994; Salive et al. 1992). However, it is of great challenge to trace the element content change. Thus, we investigated element concentrations in the hair of healthy centenarians and their offspring to reflect the element change with age.

Hainan Island, recognized by the International Expert Committee on Population Aging and Longevity as a World Longevity Island on August 27, 2014 (Xinhua) for its highest percentage of centenarians $(18.75 / 100,000)$ in China (China NBS 2011), was chosen as the study area because it had the highest proportion of centenarians in China. The objectives of this study were (1) to analyze the concentration of 5 major elements $(\mathrm{Ca}, \mathrm{P}, \mathrm{K}, \mathrm{Mg}$, and $\mathrm{Na})$ and 10 trace elements (Cd, Cr, Cu, Fe, Mn, Ni, Pb, Se, Sr, and $\mathrm{Zn}$ ) in the hair of healthy centenarians, (2) to evaluate the correlation between a centenarian's age and element concentrations in hair, (3) to ascertain the key 
element(s) associated with centenarian life span, and (4) to examine the effects of generation and other confounders such as age, sex, education level, smoking habits, alcohol intake, and frequency of hospitalization on element concentrations. In addition, a set of baseline data from healthy centenarians may provide a valid reference for diseased subjects, leading to improved diagnoses and more effective therapies and supporting policies on health and aging (Li et al. 2011; Savarino et al. 2001).

\section{Materials and methods}

Study area

Hainan Island is a province at the southern tip of China with an area of $35,100 \mathrm{~km}^{2}$, a latitude of $18^{\circ} 10^{\prime}$ to $20^{\circ} 10^{\prime}$ North, and a longitude from $108^{\circ} 37^{\prime}$ to $111^{\circ} 05^{\prime}$ East. The climate is tropical monsoon with an average annual rainfall of 1600-2500 $\mathrm{mm}$ and average annual temperature of $23-25^{\circ} \mathrm{C}$ (Jiang et al. 2014).

According to the demographic database of the sixth Chinese census, there are 1162 centenarians in Hainan Island and their prevalence per 100,000 people (C/ 100,000 ) is 13.40 (China NBS), with both values ranking highest in China (Fig. 1). At a county level, the highest $\mathrm{C} / 100,000$ is in Lingao (36.93), followed by Chengmai (31.04) and Wanning (20.34), and the lowest is in Baoting (2.73) and Sanya (3.21). Even the lowest value is slightly higher than the national average of 2.70/100,000. Although the counties with high $\mathrm{C} / 100,000$ are dispersed, they are mainly located in eastern Hainan Island.

In addition, the majority of centenarians are native and unlikely to migrate or have lived outside this region during their lifetime. The primary environment in this region is well protected, as there is a low level of industrial activity.

Sample collection and preparation

The study was conducted on relatively healthy centenarians throughout Hainan Island in January 2013, and all participants were interviewed in person at their residence. A "relatively healthy centenarian" was defined based on a modified version of the criteria developed by Darviri et al. (2008) as follows: (1) capable of volunteering for the study, (2) capable of adequately communicating with the interviewer and granting an interview, (3) not bedridden, (4) having no measurable functional or cognitive limitations, and (5) living at his/her current address for at least 10 years. In addition, no proxy interviews occurred and no
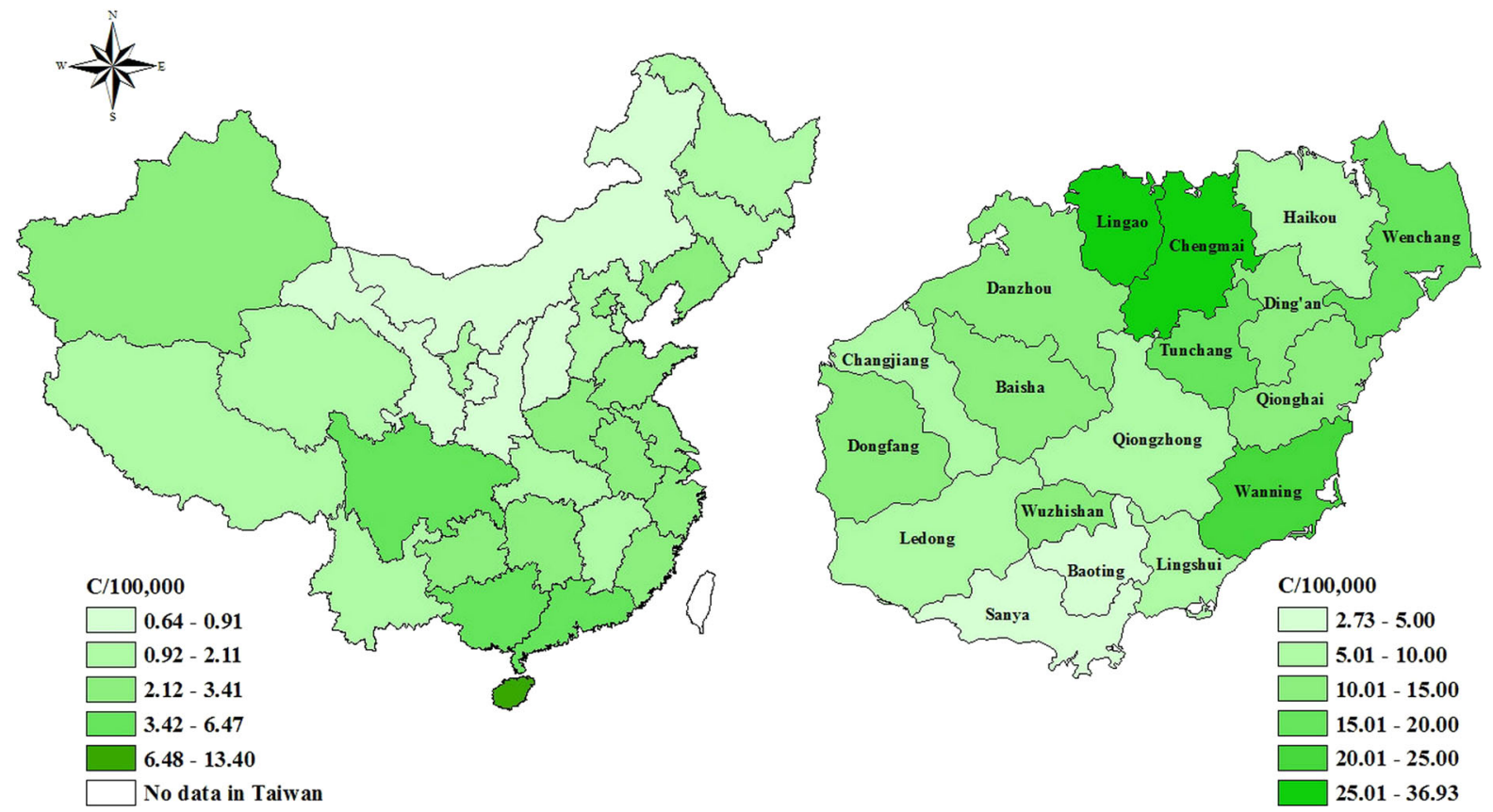

Fig. 1 Distribution of centenarians per 100,000 people in China (left) and Hainan Island (right) 
institutionalized centenarians were included. All study participants from the different communities were informed about the objectives of this study and agreed to collaborate, and the present study was approved by the bioethics committee of the Institute of Geographical Sciences and Natural Resource Research, Chinese Academy of Sciences (Beijing, China). Subjects answered a structured questionnaire containing questions on sociodemographic characteristics, education level, smoking habits, alcohol intake, and health status. In total, 255 hair samples and questionnaires were collected. Hair samples from the children and grandchildren of 124 centenarians were also collected.

Hair samples were collected from the nape of the neck, as near as possible to the scalp, with a pair of stainless steel scissors, and stored in polyethylene bags for later analysis. Hair filaments were cut into lengths $<2 \mathrm{~mm}$ using stainless steel scissors and washed thoroughly in an ultrasonic bath with $2 \%$ nonionic detergent, followed by Milli-Q water. Washed samples were placed on Whatman filter paper and dried at room temperature in a class 100 laminar-flow hood.

\section{Analytical methods}

All reagents were of analytical grade or better. Highpurity deionized water from a Milli-Q Plus filter (Millipore, Bedford, MA, USA) was used for all dilutions and washes. All implements used in sample preparation were prewashed in a $5 \%$ nitric acid solution. All measurements and analyses were performed at the Centre for Physical and Chemical Analysis, Institute of Geographical Sciences and Natural Resource Research, Chinese Academy of Sciences (Beijing, China). For multielement analysis, approximately $0.2 \mathrm{~g}$ dried hair from each sample was placed in a 50-mL beaker and digested in $3 \mathrm{~mL}$ nitric acid/hydrogen peroxide solution (2:1 V/V). Samples were carefully evaporated to near dryness on an electric heating plate at $100 \pm 5{ }^{\circ} \mathrm{C}$. The residue was transferred to a $10-\mathrm{mL}$ metal-free polyethylene bottle (Nunc $^{\mathrm{TM}}$, Roskilde, Denmark) and diluted with MilliQ water for later analysis. Blank samples were prepared following the same procedure without hair. Concentrations of $\mathrm{Cd}, \mathrm{Cr}, \mathrm{Cu}, \mathrm{Mn}, \mathrm{Ni}, \mathrm{Pb}$, and Se were measured by Optima 5300DV inductively coupled plasma mass spectrometry (PerkinElmer, Waltham, MA, USA) (Goulle et al. 2005; Li et al. 2011), and concentrations of $\mathrm{Ca}, \mathrm{Fe}, \mathrm{K}, \mathrm{Mg}, \mathrm{P}, \mathrm{Na}, \mathrm{Sr}$, and $\mathrm{Zn}$ were measured by Elan DRC-e inductively coupled plasma optical emission spectrometry (PerkinElmer) (Suleiman et al. 2007). Meticulous care was taken to avoid external contamination of samples during analytical procedures. For quality assurance and control, blank spikes, certified reference materials (CRM, human hair powder GBW 09101, obtained from the National Standard Sample Study Center in Beijing, China), and blind duplicates were used during analyses. The recoveries on spiked samples of the 15 metals ranged from 83 to $108 \%$, and the relative percentage differences were $<11 \%$ in duplicate samples. The limits of detection for the metals were $0.002-0.017 \mu \mathrm{g} \mathrm{L}^{-1}$, which were determined as three times the standard deviation from seven blank solutions.

\section{Statistical methods}

Kolmogorov-Smirnov tests were performed to determine whether the distribution for each element was normal and log-transformed concentrations were used to normalize their distribution. Spearman's rank correlation was for evaluating the correlation between a centenarian's age and the element concentrations in hair. A stepwise multiple linear regression (MLR) analysis was used to identify the element(s) significantly associated with the life span of centenarians. Samples were classified by confounders (generation, age, sex, education level, smoking habits, alcohol intake, and frequency of hospitalization). Statistical tests ( $t$ test or ANOVA) were performed to detect significant differences $(p<0.05)$ of the geometric means of categorized, and linear regression analysis was used.

All statistical analyses were performed using SPSS 16.0 for Windows (IBM, Chicago, IL, USA). The statistical significance was set at $p<0.05$. In addition, ArcGIS version 10.0 (Esri, Redlands, CA, USA) software was used to generate distribution maps of longevity indexes and element concentration.

\section{Results and discussion}

Descriptive statistics for element concentrations in the hair of healthy centenarians

The descriptive statistics for element concentrations in hair samples from 255 healthy centenarians living in 
Table 1 Element concentrations in healthy centenarians' hair, $\mathrm{mg} / \mathrm{kg}$ $(N=255)$
$A M$ arithmetic mean, $G M$ geometric mean, Min minimum, Max maximum, $P 5$ 5th percentile, P50 50th percentile, $P 9595$ th percentile, $S D$ standard deviation

\begin{tabular}{lcccccccc}
\hline & \multicolumn{1}{l}{ AM } & \multicolumn{1}{l}{ GM } & \multicolumn{1}{l}{ Min } & \multicolumn{1}{l}{ Max } & \multicolumn{1}{l}{ P5 } & P50 & P95 & \multicolumn{1}{c}{ SD } \\
\hline $\mathrm{Ca}$ & 1693.40 & 1470.47 & 226.35 & 4215.32 & 475.03 & 1550.49 & 3632.90 & 875.31 \\
$\mathrm{Cd}$ & 0.069 & 0.055 & 0.011 & 0.236 & 0.023 & 0.050 & 0.220 & 0.053 \\
$\mathrm{Cr}$ & 3.82 & 2.93 & 0.37 & 13.70 & 0.65 & 3.68 & 8.12 & 2.61 \\
$\mathrm{Cu}$ & 8.65 & 8.24 & 2.07 & 25.93 & 5.28 & 8.09 & 15.03 & 3.14 \\
$\mathrm{Fe}$ & 66.35 & 45.04 & 6.96 & 421.25 & 12.15 & 45.87 & 181.91 & 75.29 \\
$\mathrm{~K}$ & 60.65 & 31.31 & 3.18 & 521.60 & 6.17 & 30.74 & 256.21 & 89.32 \\
$\mathrm{Mg}$ & 257.51 & 222.70 & 23.26 & 691.82 & 76.40 & 228.37 & 548.34 & 138.59 \\
$\mathrm{Mn}$ & 4.01 & 2.25 & 0.44 & 24.82 & 0.50 & 1.90 & 17.63 & 5.19 \\
$\mathrm{Na}$ & 202.92 & 130.70 & 15.83 & 1178.29 & 22.15 & 126.97 & 773.07 & 225.28 \\
$\mathrm{Ni}$ & 1.24 & 0.85 & 0.09 & 4.10 & 0.13 & 0.96 & 3.40 & 1.00 \\
$\mathrm{P}$ & 153.66 & 148.74 & 61.13 & 345.27 & 101.90 & 147.30 & 238.41 & 40.99 \\
$\mathrm{~Pb}$ & 1.942 & 1.370 & 0.406 & 7.044 & 0.472 & 1.242 & 6.194 & 1.760 \\
$\mathrm{Se}$ & 0.418 & 0.395 & 0.034 & 0.805 & 0.214 & 0.409 & 0.629 & 0.130 \\
$\mathrm{Sr}$ & 7.74 & 6.41 & 1.16 & 23.86 & 2.15 & 6.43 & 18.46 & 4.91 \\
$\mathrm{Zn}$ & 175.06 & 165.79 & 42.65 & 417.81 & 90.78 & 170.59 & 290.14 & 57.66 \\
\hline
\end{tabular}

Table 2 Spearman's correlation coefficients for age and elements in hair of centenarians

\begin{tabular}{llllllllllllllll}
\hline & $\mathrm{Ca}$ & $\mathrm{Cd}$ & $\mathrm{Cr}$ & $\mathrm{Cu}$ & $\mathrm{Fe}$ & $\mathrm{K}$ & $\mathrm{Mg}$ & $\mathrm{Mn}$ & $\mathrm{Na}$ & $\mathrm{Ni}$ & $\mathrm{P}$ & $\mathrm{Pb}$ & $\mathrm{Se}$ & $\mathrm{Sr}$ & $\mathrm{Zn}$ \\
\hline Age & 0.03 & -0.01 & 0.09 & 0.02 & 0.10 & 0.01 & -0.02 & -0.01 & 0.02 & 0.12 & -0.09 & -0.05 & 0.06 & 0.1 & 0.06 \\
\hline
\end{tabular}

Hainan Island are presented in Table 1. The concentration of Se was normally distributed, while the concentrations of the other elements were not.

Reference values (RVs) and reference intervals (RIs) were defined according to the International Federation of Clinical Chemistry (Poulsen et al. 1997). Because a reliable set of reference standards was not available for element concentrations in hair of centenarians in Hainan, the geometric mean values obtained here were used as RVs. RIs, defined as the prediction interval between which $95 \%$ of values of the reference group were found (Poulsen et al. 1997), are presented in Table 1.

Factors such as sex, age, ethnicity, hair type, and geographical location can affect reference ranges and thus may influence the final values (Mikulewicz et al. 2013). Therefore, follow-up evaluations should be conducted to verify the RVs and RIs of elements in the hair of this population. Nonetheless, the values obtained are useful and will enable further studies on the manipulation of element concentrations in body tissues as a potential therapeutic modality in geriatric disease.
Relationship between age and element concentrations

Spearman's rank correlation was used to evaluate the relationship between age and element concentration (Table 2). Positive correlations were seen between age and $\mathrm{Ca}, \mathrm{Cr}, \mathrm{Cu}, \mathrm{Fe}, \mathrm{K}, \mathrm{Na}, \mathrm{Ni}, \mathrm{Se}, \mathrm{Sr}$, and $\mathrm{Zn}$ concentrations, while negative correlations were seen for age and $\mathrm{Cd}, \mathrm{Mg}, \mathrm{Mn}, \mathrm{P}$, and $\mathrm{Pb}$ concentrations. However, these correlations were not statistically significant.

Stepwise MLR was used to ascertain the association between element concentrations and life span, using centenarians' age as the dependent variable and the 15 elements measured as the independent variables (Li et al. 2011). The statistical model and parameters associated with the final step of the stepwise MLR, which represented the best explanatory independent variables, were as follows: $\tilde{Y}$ (centenarians' age) $=104.017-$ $0.010 \mathrm{P}-0.154 \mathrm{~Pb}+0.003 \mathrm{Fe}+1.460 \mathrm{Se}$, with $R^{2}=$ $0.035, F(4,250)=2.29$, and $p<0.05$.

The final 4 selected independent variables in this model were $\mathrm{P}, \mathrm{Pb}, \mathrm{Fe}$, and $\mathrm{Se}$. $\mathrm{P}$ and $\mathrm{Pb}$ had the highest 


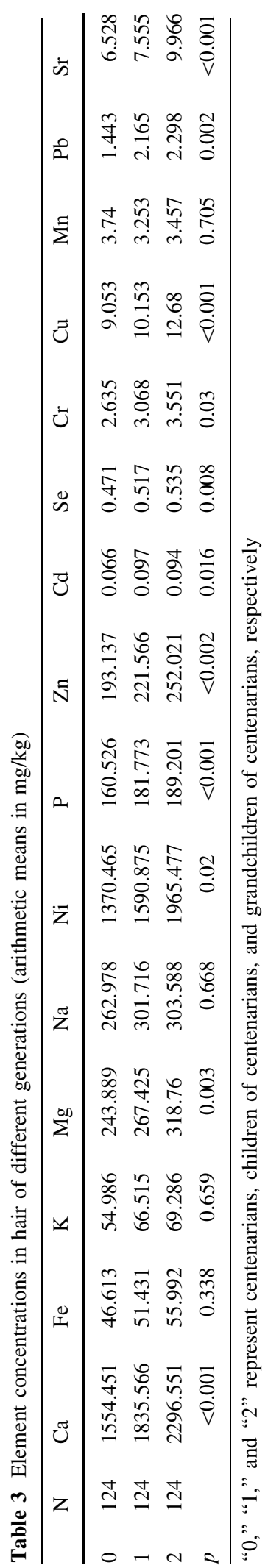

Fig. 2 Comparison of element concentration in hair between generations. The bars represent the standard deviations of elements for each generation. Different letters mean significant differences at $p<0.05$ as determined by Student's $t$ test

and second highest weight, respectively, and had a negative effect on longevity. In contrast, $\mathrm{Fe}$ and $\mathrm{Se}$ concentrations were positively associated with longevity. The model excluded other elements due to their low relative contribution. It can be concluded that $\mathrm{Fe}$ and Se play an important role in maintaining metabolic homeostasis in centenarians and contribute positively to their life span, and excessive consumption of $\mathrm{P}$ and $\mathrm{Pb}$ is harmful to health and may reduce life span.

Se is an essential nutrient, and adequate amounts are required for optimal health (Papp et al. 2007). It acts as a potent antioxidant protecting cells from oxygen free radicals and thus can slow the aging process (Hamilton et al. 2000; Yoshizawa et al. 1998). Fe functions in several biological systems such as the sensory systems. It can also cause harm through oxidative stress, interference with the absorption or metabolism of other nutrients, and suppression of critical enzymatic activities. Its deficiency is considered an important risk factor for health (Iannotti et al. 2006).

Heavy metals have long been recognized as harmful environmental pollutants (ADSTR 2007). Pb can impair visual space cognition in centenarians, which might be an early symptom of dementia (Weisskopf et al. 2007; Wright et al. 2003), and in this study, it was found to have an adverse influence on centenarian age. Although $\mathrm{P}$ is considered an essential element, according to previous research, a high serum phosphate concentration is significantly associated with cardiovascular disease and increased mortality (Block et al. 1998; Kestenbaum et al. 2005; Slinin et al. 2005), and an elevation in $\mathrm{P}$ can trigger the secretion of regulatory hormones, leading to tissue damage and the development of cardiovascular disease, renal impairment, and bone loss (Calvo et al. 2014). Thus, excessive consumption of $\mathrm{Pb}$ and $\mathrm{P}$ should be avoided.

Intergenerational transmission of elements

To analyze differences between generations, element concentrations in hair were compared between centenarians and their offspring who lived in the same area and 

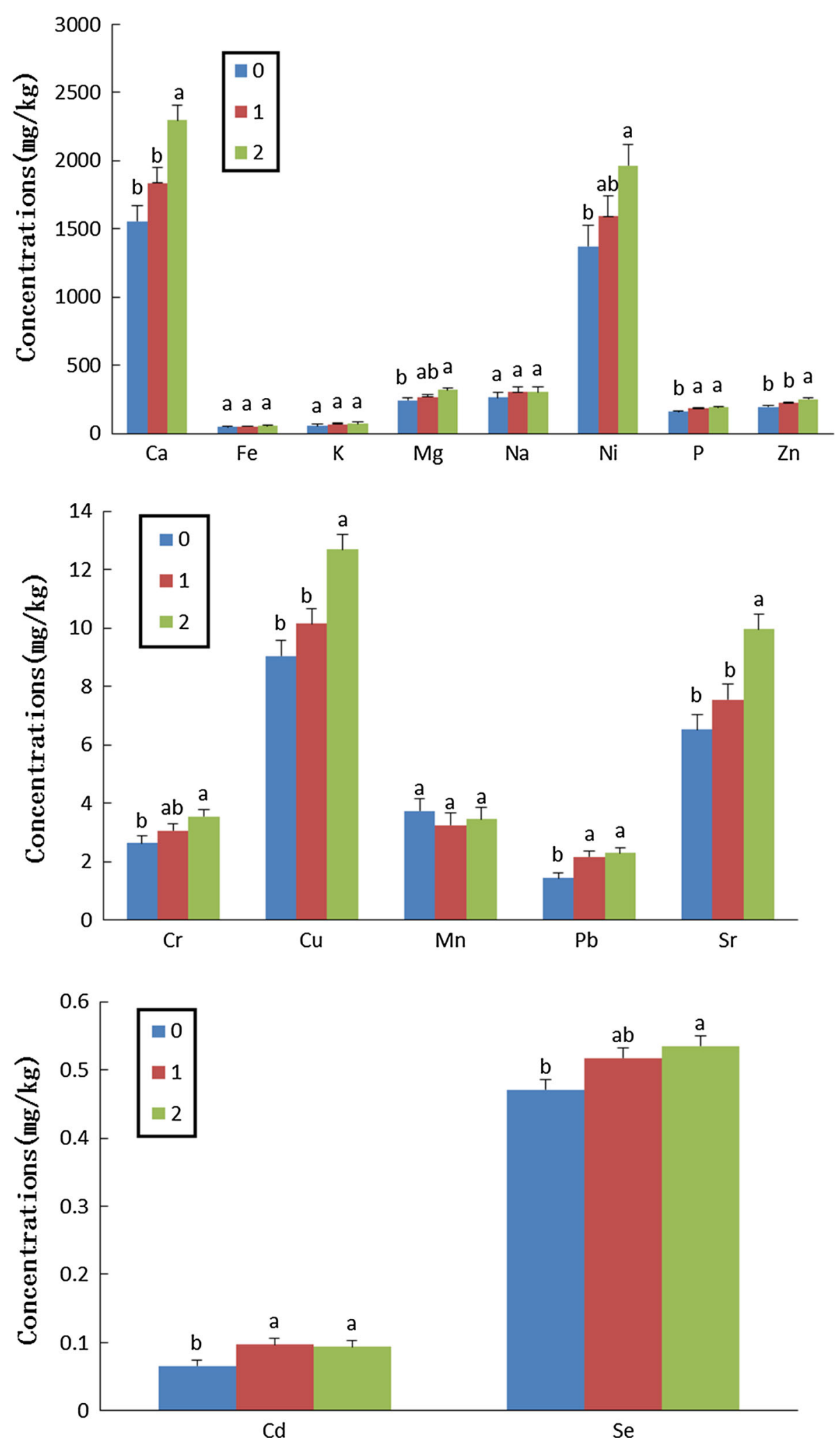
were exposed to a similar environment and culture. These results are illustrated in Table 3 and Fig. 2. For almost all elements except for $\mathrm{Fe}, \mathrm{K}, \mathrm{Na}$, and $\mathrm{Mn}$, concentrations were significantly highest in grandchildren's hair, followed by children's hair, and finally centenarians' hair $(p<0.05)$. Our findings are similar to the results illustrated by other researchers (Mertz 1997; Preziosi et al. 1994; Salive et al. 1992) who found that element concentrations in the body might decrease with age.

Individual factors influencing element concentrations in centenarian hair

Interindividual variation in concentrations of elements in hair is a result of multifactorial comprehensive action. This study identified a number of factors associated with element concentrations. Table 4 shows element concentrations in relation to sex, age, education level, smoking habits, alcohol intake, and frequency of hospitalization.

The proportion of females $(83.44 \%)$ was much higher than that of males (16.56\%). According to the previous research, females might live longer as a result of disproportionately high mortality levels in males (Ginter and Simko 2013; Luy and Gast 2014). Sex differences in diet, iron status, and hormone levels can affect the absorption of elements (Kazi et al. 2008; Olsson et al. 2002). Element concentrations of Ca, Cd, $\mathrm{Cu}, \mathrm{K}, \mathrm{Mg}, \mathrm{Mn}, \mathrm{Se}$, and $\mathrm{Sr}$ were higher in females than in males, while those of $\mathrm{Cr}, \mathrm{Fe}, \mathrm{Na}, \mathrm{Ni}, \mathrm{P}, \mathrm{Pb}$, and $\mathrm{Zn}$ were higher in men. Differences were statistically significant for $\mathrm{Ca}, \mathrm{Cr}, \mathrm{Mg}, \mathrm{Mn}, \mathrm{P}, \mathrm{Se}$, and $\mathrm{Sr}$.

The 255 centenarians were divided into 3 age groups, 100-103, 104-107, and over 108 years old. The differences between age groups were not statistically observable except for $\mathrm{Zn}$, which might because the age differences in the present study were too small. Thus, it does not merit additional discussion here.

Education level was used as an indicator of socioeconomic status, which may affect element concentrations due to associated differences in dietary patterns, lifestyle, and occupational exposure (Brulle and Pellow 2006). In our study, centenarians were divided into 3 groups according to different education levels, which were uneducated centenarians, centenarians completed primary or secondary studies. Of the centenarians in this study, $92.09 \%$ were defined as uneducated, most likely because they had lived through a period in which education was neglected.
Although differences in $\mathrm{Cr}$ and $\mathrm{Mn}$ concentration were significant $(p<0.05)$, they showed no obvious trend in common. Educational level is a complex variable that may be a surrogate for other covariates, measured or unmeasured in this analysis, and many of these associations are difficult to explain. The variations might be due to the different and rather complex incorporation kinetics of elements, which has not been studied or elucidated in detail so far.

Drinking alcohol and smoking are widely recognized health risks (Aguilera et al. 2008). It has been previously reported that smoking clearly influences $\mathrm{Cd}$ concentrations (Hoffmann et al. 2000), which is wellknown nephrotoxic element and significantly changes in biomarkers of early kidney damage. Alcohol appeared a residual effect of dietary patterns (Aguilera et al. 2008). In this study, the majority of centenarians were never smokers $(91.72 \%)$ and nondrinkers (76.43\%), confirming that a healthy lifestyle contributed to longevity. We found higher levels of $\mathrm{Ca}$, $\mathrm{Cd}, \mathrm{Cr}, \mathrm{K}, \mathrm{Mn}, \mathrm{Ni}, \mathrm{P}, \mathrm{Pb}$, and $\mathrm{Sr}$ in smokers than in those who never smoked. In contrast, concentrations of $\mathrm{Cu}, \mathrm{Fe}, \mathrm{Mg}, \mathrm{Na}, \mathrm{Se}$, and $\mathrm{Zn}$ were lower in smokers. Except for $\mathrm{Fe}$ and $\mathrm{Ni}$, drinking can increase the load of element concentrations. However, differences in element concentrations based on alcohol intake and smoking habits were not statistically significant, and thus, more research is needed to identify the mechanisms involved in the effects of smoking and drinking on centenarian longevity.

It has been reported that most centenarians maintain a healthy lifestyle (Franchini and Mannucci 2007; Ozaki et al. 2007; Perls et al. 2002). In our study, $69.43 \%$ of the centenarians had not visited the hospital in the past year and were disability free. The frequency of hospitalization (per month) was significantly positively associated with $\mathrm{Cu}$ and $\mathrm{Pb}$ levels $(p<0.05)$.

In fact, some correlations between element concentrations and selected factors may be due to chance, or in other cases are not biologically or clinically remarkable, and the factors we considered can be influenced by other covariates. To obtain the most reliable estimate of associations between element concentrations and one categorical variable without bias from other factors, we introduced dummy variables to replace the categorical variables with numerical values and carried out linear regression analysis of log-transformed levels of elements in healthy 


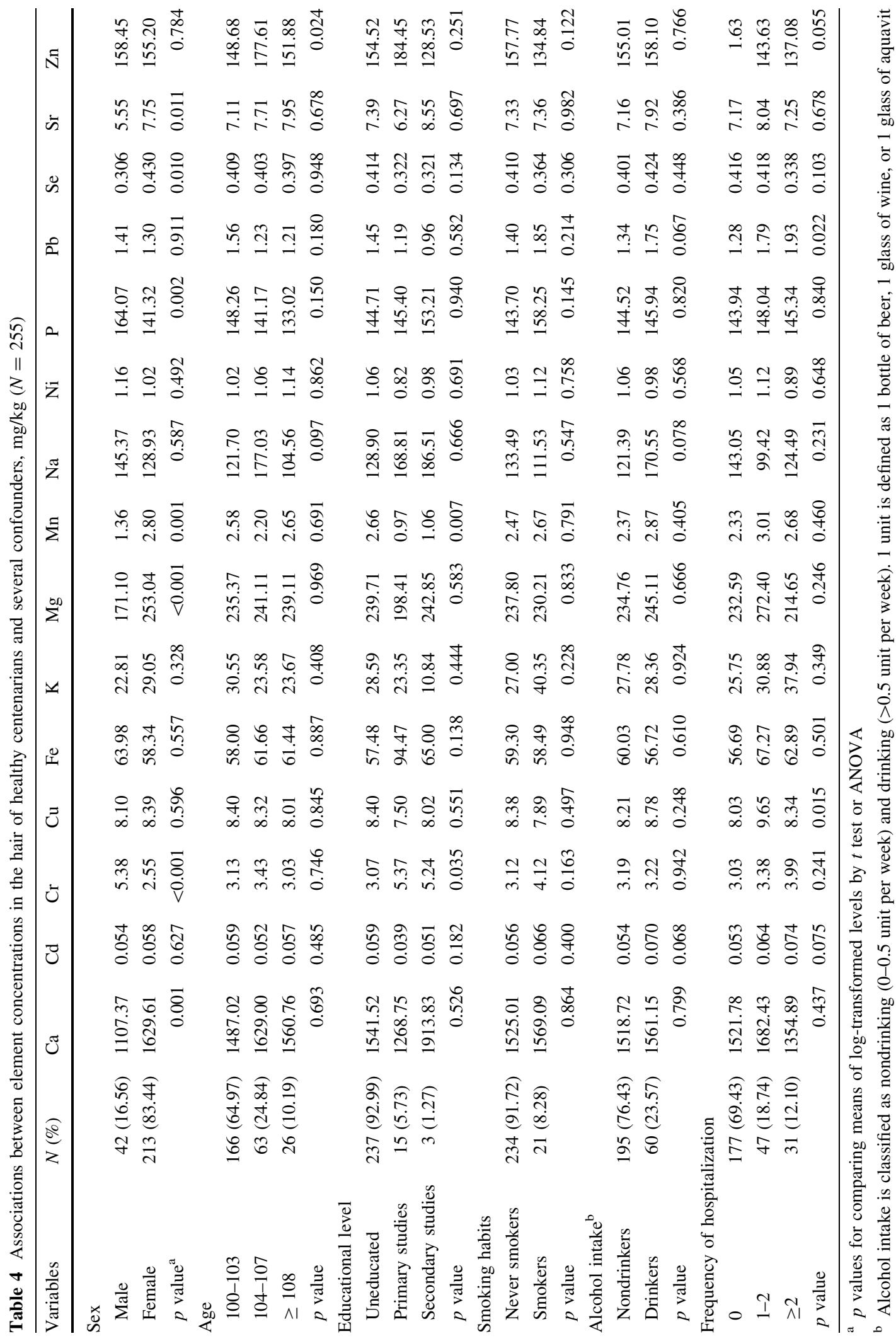




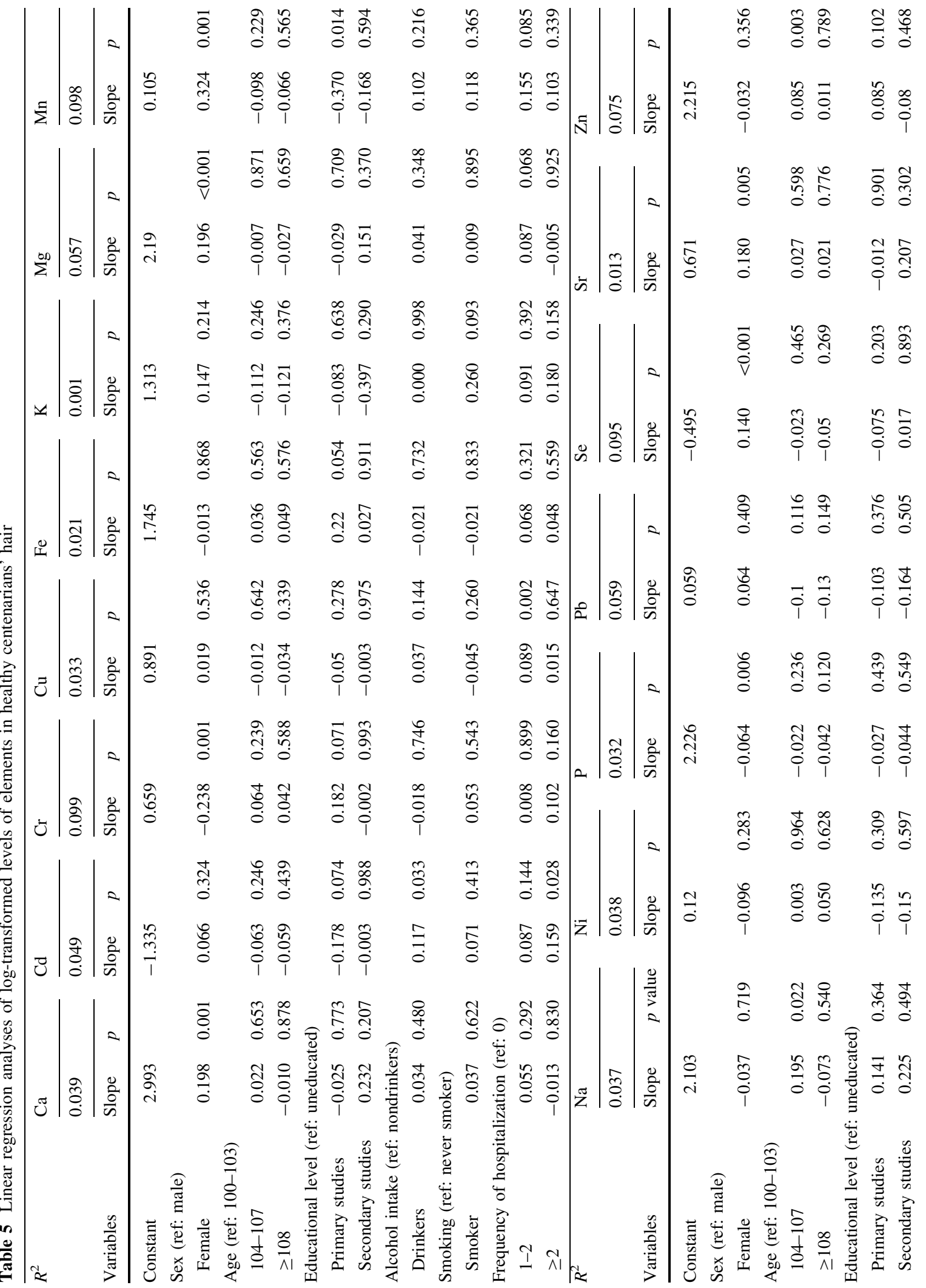




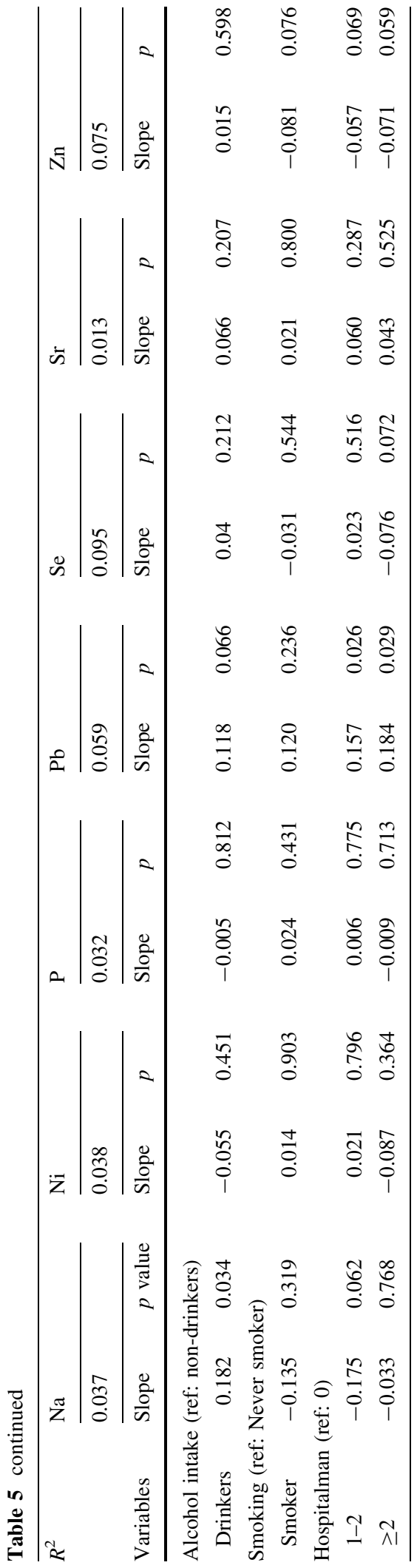

centenarians' hair (Aguilera et al. 2008). The results are summarized in Table 5. Regarding sex, female centenarians showed significantly higher levels of $\mathrm{Ca}$, $\mathrm{Mg}, \mathrm{Mn}, \mathrm{Se}$, and $\mathrm{Sr}$ and lower levels of $\mathrm{Cr}$ and $\mathrm{P}$. People aged 104-107 years old had strikingly higher levels of $\mathrm{Na}$ and $\mathrm{Zn}$ in their hair than people aged 100-103. Mn showed a direct association with educational level, with statistically significant lower levels in the primary studies group. Drinking alcohol was positively associated with $\mathrm{Cd}$ and $\mathrm{Na}$ levels, whereas smoking habits showed no significant effect on all the elements. Frequency of hospitalization was associated with $\mathrm{Cd}, \mathrm{Cu}$, and $\mathrm{Pb}$. These results also reflect that elements might differ in exposure pathways, migration, and transfer. Overall, the variables included in the models made only a small contribution to the total variance of the elements, providing a small adjusted $\mathrm{R}^{2}$.

\section{Conclusion}

In this study, we measured element concentrations in the hair of healthy centenarians in Hainan Island, China. RVs and RIs for 15 elements are presented. Our findings suggest that centenarian age is a function of $\mathrm{P}$, $\mathrm{Pb}, \mathrm{Fe}$, and $\mathrm{Se}$ concentrations in their hair, of which $\mathrm{Fe}$ and $\mathrm{Se}$ had a positive association with life span, whereas excessive concentrations of $\mathrm{P}$ and $\mathrm{Pb}$ were harmful to health and had a negative association with life span. Moreover, element loads in hair increased significantly with intergenerational transmission (i.e., centenarians $<$ children $<$ grandchildren).

Interindividual variation in element concentrations in hair is the result of many factors, such as sex, education level, and drinking and smoking habits. There were more females than males centenarians in our study. Concentrations of $\mathrm{Ca}, \mathrm{Mg}, \mathrm{Mn}, \mathrm{Se}$, and $\mathrm{Sr}$ were significantly higher in the females' hair than in males' hair, while levels of $\mathrm{Cr}$ and $\mathrm{P}$ in females were lower. Most centenarians were uneducated, and the Mn level was statistically significantly lower in the primary studies group compared with the uneducated group. Most of the centenarians in our study did not drink alcohol or smoke. Alcohol intake was positively associated with $\mathrm{Cd}$ and $\mathrm{Na}$ levels, whereas smoking habits were not significantly associated with any of the elements. Furthermore, $69.43 \%$ of centenarians were disability free and never visited the hospital, but for 
those who had been hospitalized, the frequency of hospitalization (per month) was significantly associated with $\mathrm{Cd}, \mathrm{Cu}$, and $\mathrm{Pb}$ concentrations.

Although our results are inconclusive due to insufficient data, we believe our findings will improve understanding of the causes of aging and, as a result, provide valuable information for the development of more effective approaches for successful aging.

Acknowledgments This work was supported by the National Science Foundation of China (No. 41171082).

\section{References}

Aguilera, I., Daponte, A., Gil, F., Hernandez, A. F., Godoy, P., Pla, A., et al. (2008). Biomonitoring of urinary metals in a population living in the vicinity of industrial sources: A comparison with the general population of Andalusia, Spain. Science of the Total Environment, 407, 669-678.

Ahluwalia, N., Gordon, M. A., Handte, G., Mahlon, M., Li, N. Q., Beard, J. L., et al. (2000). Iron status and stores decline with age in Lewis rats. Journal of Nutrition, 130, 2378-2383.

Andersen, S. L., Sebastiani, P., Dworkis, D. A., Feldman, L., \& Perls, T. T. (2012). Health span approximates life span among many supercentenarians: Compression of morbidity at the approximate limit of life span. Journals of Gerontology Series a-Biological Sciences and Medical Sciences, 67, 395-405.

Andersen-Ranberg, K., Vasegaard, L., \& Jeune, B. (2001). Dementia is not inevitable: A population-based study of Danish centenarians. Journals of Gerontology Series B-Psychological Sciences and Social Sciences, 56, 152-159.

Beard, J., Biggs, S., Bloom, D. E., Fried, L. P., Hogan, P. R., Kalache, A., et al. (2011). Global population ageing: Peril or promise?Geneva: World Economic Forum.

Block, G. A., Hulbert-Shearon, T. E., Levin, N. W., \& Port, F. K. (1998). Association of serum phosphorus and calcium $\mathrm{X}$ phosphate product with mortality risk in chronic hemodialysis patients: A national study. American Journal of Kidney Diseases, 31, 607-617.

Brulle, R. J., \& Pellow, D. N. (2006). Environmental justice: Human health and environmental inequalities. Annual Review of Public Health, 27, 103-124.

Calvo, M. S., Moshfegh, A. J., \& Tucker, K. L. (2014). Assessing the health impact of phosphorus in the food supply: Issues and considerations. Advances in Nutrition, 5, 104-113.

China NBS-National Bureau of Statistics of China. (2001). The fifth national population census of the People's Republic of China.

China NBS-National Bureau of Statistics of China. (2011). The sixth national population census of the People's Republic of China.
Christensen, K., \& Vaupel, J. W. (1996). Determinants of longevity: Genetic, environmental and medical. Journal of Internal Medicine, 240, 333-341.

Darviri, C., Demakakos, P., \& Charizani, F. (2008). Assessment of the health status of Greek centenarians. Archives of Gerontology and Geriatrics, 46, 67-78.

Evert, J., Lawler, E., Bogan, H., \& Perls, T. (2003). Morbidity profiles of centenarians: Survivors, delayers, and escapers. Journals of Gerontology Series a-Biological Sciences and Medical Sciences, 58, 232-237.

Franchini, M., \& Mannucci, P. M. (2007). Short-term effects of air pollution on cardiovascular diseases: Outcomes and mechanisms. Journal of Thrombosis and Haemostasis, 5, 2169-2174.

Ginter, E., \& Simko, V. (2013). Women live longer than men. Bratislava Medical Journal-Bratislavske Lekarske Listy, 114, 45-49.

Goulle, J. P., Mahieu, L., Castermant, J., Neveu, N., Bonneau, L., Laine, G., et al. (2005). Metal and metalloid multielementary ICP-MS validation in whole blood, plasma, urine and hair-Reference values. Forensic Science International, 153, 39-44.

Hamilton, I. M. J., Gilmore, W. S., \& Strain, J. J. (2000). Marginal copper deficiency and atherosclerosis. Biological Trace Element Research, 78, 179-189.

Hoffmann, K., Becker, K., Friedrich, C., Helm, D., Krause, C., \& Seifert, B. (2000). The German Environmental Survey 1990/1992 (GerES II): Cadmium in blood, urine and hair of adults and children. Journal of Exposure Analysis and Environmental Epidemiology, 10, 126-135.

Iannotti, L. L., Tielsch, J. M., Black, M. M., \& Black, R. E. (2006). Iron supplementation in early childhood: Health benefits and risks. American Journal of Clinical Nutrition, 84, 1261-1276.

Jiang, W., Hou, Q. Y., Yang, Z. F., Yu, T., Zhong, C., Yang, Y., et al. (2014). Annual input fluxes of heavy metals in agricultural soil of Hainan island, China. Environmental Science and Pollution Research, 21, 7876-7885.

Kazi, T. G., Afridi, H. I., Kazi, N., Jamali, M. K., Arain, M. B., Jalbani, N., et al. (2008). Copper, chromium, manganese, iron, nickel, and zinc levels in biological samples of diabetes mellitus patients. Biological Trace Element Research, 122, 1-18.

Kestenbaum, B., Sampson, J. N., Rudser, K. D., Patterson, D. J., Seliger, S. L., Young, B., et al. (2005). Serum phosphate levels and mortality risk among people with chronic kidney disease. Journal of the American Society of Nephrology, 16, 520-528.

Li, Y. H., Yang, L. S., Wang, W. Y., Li, H. R., Lv, J. M., \& Zou, X. Y. (2011). Trace element concentrations in hair of healthy Chinese centenarians. Science of the Total Environment, 409, 1385-1390.

Li, Y. H., Zou, X. Y., Lv, J. M., Yang, L. S., Li, H. R., \& Wang, W. Y. (2012). Trace elements in fingernails of healthy Chinese centenarians. Biological Trace Element Research, $145,158-165$.

Luy, M., \& Gast, K. (2014). Do women live longer or do men die earlier? Reflections on the causes of sex differences in fife expectancy. Gerontology, 60, 143-153. 
Mertz, W. (1997). Confirmation: Chromium levels in serum, hair, and sweat decline with age. Nutrition Reviews, 55, 373-375.

Mikulewicz, M., Chojnacka, K., Gedrange, T., \& Gorecki, H. (2013). Reference values of elements in human hair: A systematic review. Environmental Toxicology and Pharmacology, 36, 1077-1086.

Motta, M., Bennati, E., Ferlito, L., Malaguarnera, M., Motta, L., \& IMUSCE. (2005). Successful aging in centenarians: Myths and reality. Archives of Gerontology and Geriatrics, 40, 241-251.

Olsson, I. M., Bensryd, I., Lundh, T., Ottosson, H., Skerfving, S., \& Oskarsson, A. (2002). Cadmium in blood and urineImpact of sex, age, dietary intake, iron status, and former smoking-Association of renal effects. Environmental Health Perspectives, 110, 1185-1190.

Ozaki, A., Uchiyama, M., Tagaya, H., Ohida, T., \& Ogihara, R. (2007). The Japanese centenarian study: Autonomy was associated with health practices as well as physical status. Journal of the American Geriatrics Society, 55, 95-101.

Papp, L. V., Lu, J., Holmgren, A., \& Khanna, K. K. (2007). From selenium to selenoproteins: Synthesis, identity, and their role in human health. Antioxidants \& Redox Signaling, 9, 775-806.

Perls, T., Levenson, R., Regan, M., \& Puca, A. (2002). What does it take to live to 100? Mechanisms of Ageing and Development, 123, 231-242.

Pike, J., \& Chandra, R. K. (1995). Effect of vitamin and traceelement supplementation on immune indexes in healthy elderly. International Journal for Vitamin and Nutrition Research, 65, 117-121.

Poulsen, O. M., Holst, E., \& Christensen, J. M. (1997). Calculation and application of coverage intervals for biological reference values-Technical report. Pure and Applied Chemistry, 69, 1601-1611.

Preziosi, P., Hercberg, S., Galan, P., Devanlay, M., Cherouvrier, F., \& Dupin, H. (1994). Iron status of a healthy French population: Factors determining biochemical markers. Annals of Nutrition \& Metabolism, 38, 192-202.

Robine, J. M., \& Paccaud, F. (2005). Nonagenarians and centenarians in Switzerland, 1860 2001: A demographic analysis. Journal of Epidemiology and Community Health, 59, 31-37.

Salive, M. E., Cornoni-Huntley, J., Guralnick, J. M., Phillips, C. L., Wallace, R. B., Ostfeld, A. M., et al. (1992). Anemia and hemoglobin levels in older persons: Relationship with age, gender and health status. Journal of the American Geriatrics Society, 40, 489-496.

Savarino, L., Granchi, D., Ciapetti, G., Cenni, E., Ravaglia, G., Forti, P., et al. (2001). Serum concentrations of zinc and selenium in elderly people: Results in healthy nonagenarians/centenarians. Experimental Gerontology, 36, 327-339.

Schmidt, K. (1991). Vitamins, minerals, and trace-element in elderly people. Zentralblatt für Hygiene und Umweltmedizin, 191(2-3), 327-332.
Selim, A. J., Fincke, G., Berlowitz, D. R., Miller, D. R., Qian, S. X., Lee, A., et al. (2005). Comprehensive health status assessment of centenarians: Results from the 1999 large health survey of veteran enrollees. Journals of Gerontology Series a-Biological Sciences and Medical Sciences, 60, 515-519.

Slinin, Y., Foley, R. N., \& Collins, A. J. (2005). Calcium, phosphorus, parathyroid hormone, and cardiovascular disease in hemodialysis patients: The USRDS waves 1, 3, and 4 study. Journal of the American Society of Nephrology, 16, 1788-1793.

Stathakos, D., Pratsinis, H., Zachos, L., Vlahaki, I., Gianakopoulou, A., Zianni, D., et al. (2005). Greek centenarians: Assessment of functional health status and life-style characteristics. Experimental Gerontology, 40, 512-518.

Steinmaus, C. M., Nunez, S., \& Smith, A. H. (2000). Diet and bladder cancer: A meta-analysis of six dietary variables. American Journal of Epidemiology, 151, 693-702.

Suleiman, J. S., Hu, B., Pu, X. L., Huang, C. Z., \& Jiang, Z. C. (2007). Nanometer-sized zirconium dioxide microcolumn separation/preconcentration of trace metals and their determination by ICP-OES in environmental and biological samples. Microchimica Acta, 159, 379-385.

UN DESA (United Nations, Department of Economic and Social Affairs), Population Division. (2013). World population prospects: The 2012 revision, key findings and advance tables. Working Paper No. ESA/P/WP.227.

US EPA (United States Environmental Protection Agency). (1979).Toxic trace metals in mammalian hair and nails. EPA-600/4-79-049.

Weisskopf, M. G., Proctor, S. P., Wright, R. O., Schwartz, J., Spiro, A., Sparrow, D., et al. (2007). Cumulative lead exposure and cognitive performance among elderly men. Epidemiology, 18, 59-66.

Wilhelm, M., Hafner, D., Lombeck, I., \& Ohnesorge, F. K. (1991). Monitoring of cadmium, copper, lead and zinc status in young-children using toenails-Comparison with scalp hair. Science of the Total Environment, 103, 199-207.

Wilkinson, T. J., \& Sainsbury, R. (1998). A census-based comparison of centenarians in New Zealand with those in the United States. Journal of the American Geriatrics Society, 46, 488-491.

Wright, R. O., Tsaih, S. W., Schwartz, J., Spiro, A., McDonald, K., Weiss, S. T., et al. (2003). Lead exposure biomarkers and mini-mental status exam scores in older men. Epidemiology, 14, 713-718.

Xinhua. (2014). China Exclusive: Hainan declared as "World Longevity Island".

Yoshizawa, K., Willett, W. C., Morris, S. J., Stampfer, M. J., Spiegelman, D., Rimm, E. B., et al. (1998). Study of prediagnostic selenium level in toenails and the risk of advanced prostate cancer. Journal of the National Cancer Institute, 90, 1219-1224. 